\title{
LA PROBLEMÁTICA APLICACIÓN DEL TEST DE PROPORCIONALIDAD EN LA TUTELA LABORAL DE DERECHOS FUNDAMENTALES
}

\author{
THE PROBLEMATIC APPLICATION OF PROPORTIONAL TEST IN THE \\ LABOR TUTELA OF FUNDAMENTAL RIGHTS
}

\author{
Ignacio Covarrubias Cuevas*
}

\begin{abstract}
RESUMEN: Las normas del Código del Trabajo que estructuran el procedimiento de tutela de los derechos fundamentales del trabajador no solo no consagran test de proporcionalidad alguno sino que dificultan la aplicación de los derechos como principios optimizables, al punto de que las exigencias legales reducen e incluso imposibilitan acudir al test optimizador, entre otros motivos, debido a la finalidad protectora de la tutela, pues el resguardo de los derechos del trabajador no puede depender del "peso" del derecho que aparece en contraposición, por lo que su abordaje ha de ser afrontado como si se tratara de reglas, lo cual contradice la propuesta mayoritaria de quienes promueven la tutela en Chile.
\end{abstract}

Palabras clave: Tutela de derechos fundamentales del trabajador; test de proporcionalidad; derechos fundamentales como principios

\begin{abstract}
The rules of the Labor Code that structure the legal procedure conceived to protect the fundamental rights of workers in their workplace (called "the tutela") not only do not recognize any proportionality test but also hinder the applicability of fundamental rights understood as optimising principles, to the extent that the legal rules of such statute curtail and even prevent restorting to the optimising test, among other reasons, because of the protective goal of the tutela, since the protection of the fundamental rights of workers cannot rest on the "weight" of the right that appears to be at the other end of the scale. It is therefore essential that rights must be adjudicated as rules, which contradicts the proposal of most of the authors who promote the tutela in Chile.
\end{abstract}

Key words: Tutela of fundamental rights; proportionality test, fundamental rights as principles

\section{OBJETO Y ESTRUCTURA DEL TRABAJO}

Este artículo afirma que la versión del test de proporcionalidad -la ponderación "principialista" u "optimizadora" de Alexy- promovida por buena parte de los autores de Derecho laboral difícilmente articula en los supuestos del procedimiento de tutela de derechos fundamentales en materia laboral ("tutela") y, además, riñe con la finalidad indiscutida de este reforma legislativa, cual es la protección de los derechos fundamentales del trabajador en la relación laboral.

* Doctor en Derecho, Universidad de los Andes, profesor de Derecho e investigador del Centro de Justicia Constitucional, Universidad del Desarrollo. Dirección: Av. San Ramón 2910-3, Las Condes. Correo electrónico: icovarrubias@udd.cl.

Agradezco la colaboración a mi ayudante de investigación, Nicolás Rodríguez Rioseco. 
El trabajo consta de tres secciones. La primera describe cómo el Código del Trabajo ("Código") resguarda los derechos fundamentales del trabajador con la tutela y configuró esta con los supuestos de lesión de los derechos, entre los cuales señala que la medida lesiva no sea desproporcionada. La segunda, contrasta lo que dice la ley con lo sostenido por los promotores de la tutela en Chile, quienes mayoritariamente afirma que el artículo 485 del Código consagra el test de proporcionalidad ("test" o "TP") conforme a las premisas de Alexy ${ }^{1}$, por lo que la tensión entre los derechos del trabajador y los del empleador debería afrontarse según la ponderación proporcionalista, circunscribiendo la subsunción para casos calificados.

La tercera parte problematiza, de cara a los fines de la tutela y su configuración legal, la idea de que las normas que expresan derechos fundamentales son principios y muestra la dificultosa articulación que surge entre promover los derechos fundamentales como principios y las disposiciones del Código, al punto de sostener que las exigencias del artículo 485 no calzan con la propuesta de acudir a una versión principialista de la proporcionalidad, por lo que no solo no es posible señalar que dicho cuerpo legal consagra dicho TP sino que en algunos casos lo excluye.

Si bien el trabajo contiene aspectos críticos a los derechos fundamentales como principios susceptibles de optimización y la consecuencial modalidad del test, la valoración acotada a la tutela laboral no ha de considerarse como una crítica a todas las posibilidades de empleo de la versión principialista del test ${ }^{2}$. Por último, al no consistir el presente trabajo en un análisis jurisprudencial, las sentencias citadas han sido referidas únicamente para ilustrar algunas de las afirmaciones sostenidas por el autor.

\section{LO QUE ESTABLECE EL CÓDIGO DEL TRABAJO SOBRE LA TUTELA DE DERECHOS FUNDAMENTALES DEL TRABAJADOR Y LA REFERENCIA A LA PROPORCIONALIDAD}

La Ley 20.087/2006 consagró un procedimiento destinado a tutelar el respeto y garantía de los derechos fundamentales de los trabajadores en la vigencia de la relación laboral. Se trata, según el Mensaje, de "potenciar la vigencia plena, en el ámbito jurídico-laboral, de los derechos que el trabajador detenta no solo en cuanto trabajador sino que tam-

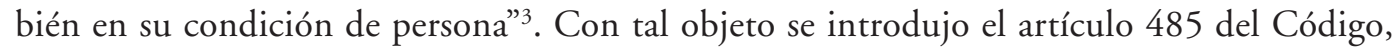
cuyo primer inciso afirma que la tutela "se aplicará respecto de las cuestiones suscitadas en la relación laboral por aplicación de las normas laborales, que afecten los derechos fundamentales de los trabajadores, entendiéndose por estos los consagrados en la Constitución

\footnotetext{
1 Aunque no es el objeto de este trabajo, es conveniente advertir que la versión alexiana del test no se corresponde con la proporcionalidad concebida y aplicada por el Tribunal Constitucional alemán, que prevé modalidades de ponderación pero que no son del todo optimizadoras en sentido de Alexy, pues no arrancan de la distinción entre principios y reglas, ni tampoco acogen la tríadica distinción de la denominada ley de ponderación del autor. Sobre las diferencias entre el test principialista y el test del TC alemán, Susnjar (2010) y Petersen (2017).

2 Una crítica general sobre aspectos teóricos y prácticos pueden encontrarse, a modo ejemplar, en: WEBBER (2009); Urbina (2012) pp. 49-80; Urbina (2014) pp. 167-192; Urbina (2017); Alvarado (2016) pp. 311-334.

3 Historia de la Ley 20.087 de 2006, p. 12.
} 
Política de la República en su artículo 19" -esta norma específica los derechos especialmente protegidos ${ }^{4}$ - "cuando aquellos derechos resulten lesionados en el ejercicio de las facultades del empleador" 5 .

El inciso segundo extiende la tutela "a los actos discriminatorios a que se refiere el artículo $2^{\circ}$ de este Código, con excepción de los contemplados en su inciso sexto" ${ }^{6}$ (que alude a una hipótesis de discriminación previa a la relación laboral). El inciso tercero dispone: " $[s]$ e entenderá que los derechos y garantías a que se refieren los incisos anteriores resultan lesionados cuando el ejercicio de las facultades que la ley le reconoce al empleador limita el pleno ejercicio de aquéllas sin justificación suficiente, en forma arbitraria o desproporcionada, o sin respeto a su contenido esencial. En igual sentido se entenderán las represalias ejercidas en contra de trabajadores, en razón o como consecuencia de la labor fiscalizadora de la Dirección del Trabajo o por el ejercicio de acciones judiciales" 7 .

El artículo 493 agrega que si en la tutela "resulten indicios suficientes de que se ha producido la vulneración de derechos fundamentales, corresponderá al denunciado explicar los fundamentos de las medidas adoptadas y de su proporcionalidad". Es clarificador el Mensaje que señala que efectuada la denuncia, "no se exige al empleador la prueba de un hecho negativo (que no violó el derecho fundamental), sino que pruebe que el acto o conducta empresarial obedeció a una motivación legítima"', además de la proporcionalidad de las medidas adoptadas que infrinjan derechos.

Parece claro que las disposiciones citadas sobre la tutela persiguen proteger los derechos fundamentales del trabajador $y$, en segundo término, no aluden a ningún test ni principio de proporcionalidad. Únicamente señalan que las medidas adoptadas por el empleador que limiten el ejercicio de los derechos del trabajador se entenderán vulneradoras de estos si son desproporcionadas, además de otros requisitos.

\section{LO QUE AFIRMAN LOS LABORALISTAS SOBRE LA TUTELA LABORAL Y LA PROPORCIONALIDAD}

\section{La tUTELA CONSAGRA O CONDUCE AL TEST DE PROPORCIONALIDAD EN SU VERSIÓN ALEXIANA}

Algunos señalan derechamente que el artículo 485 del Código establece "[l]a consagración del principio de proporcionalidad como método para resolver la colisión de dere-

\footnotetext{
4 Código del Trabajo, artículo 485, inciso 1 . Se refiere las normas de la CPR que reconocen varios derechos fundamentales, entre otros, el derecho a la vida y a la integridad física y psíquica, a la vida privada y a la honra de la persona y su familia, a la inviolabilidad de toda forma de comunicación privada, libertad religiosa, de emitir opinión e informar, de trabajo, su libre elección "y a lo establecido en su inciso cuarto", sobre la prohibición de ciertos trabajos y de exigir la afiliación o desafiliación como requisito para desarrollar una actividad o trabajo.

5 Código del Trabajo, artículo 485, inciso 1.

6 Código del Trabajo, artículo 485, inciso 2. El inciso 6 se refiere a "las ofertas de trabajo efectuadas por un empleador", que condicionen la postulación a admitir las causales de discriminación del inciso 4.

7 Código del Trabajo, artículo 485, inciso 3.

8 Código del Trabajo, artículo 493, inciso único.

9 Historia de la Ley 20.087 de 2006, Mensaje del Presidente de la República, p. 26, disponible en: http:// www.leychile.cl/Consulta/portada hl?tipo norma=XX1\&nro ley=20087\&anio=2016
} 
chos fundamentales entre el trabajador y el empleador" ${ }^{10}$. Algunos lo explicitan concibiendo los derechos fundamentales como principios y no como reglas, con lo que la adopción de esta premisa implica ${ }^{11}$. Con prescindencia de estos matices, concuerdan en que el test es fruto de adherir a la idea de que los derechos fundamentales son principios y las colisiones de principios (entre derechos o entre estos y fines constitucionalmente legítimos) deben abordarse según la proporcionalidad, lo que excluye la subsunción o delimitación, método propio de los conflictos de reglas ${ }^{12}$. Solo uno de ellos promueve el uso del TP con rasgos que no lo comprometen del todo con la modalidad alexiana ${ }^{13}$.

$\mathrm{Al}$ proclamar la eficacia directa y horizontal de los derechos fundamentales al interior de la empresa ${ }^{14}$, se afirma que el TP es el estándar para adjudicar en la tutela y que su adopción se sigue de adherir a la idea de los derechos fundamentales como principios (que denominaremos versión "principialista", "alexiana" u "optimizadora"15). Su premisa axial emana de la distinción entre principios y reglas ${ }^{16}$. Gamonal fue pionero en señalar que el artículo 485, inciso tercero, del Código debe ser examinado "desde la óptica de la ponderación de derechos y del principio de proporcionalidad", luego de lo que asume la ponderación de derechos como una "colisión de principios, caso en el cual (...) debe analizarse cuál de los principios en juego debe ceder frente a otro", y que "[p]ara estos efectos adherimos a la distinción de Alexy entre reglas y principios"17.

A partir de la distinción entre principios y reglas, afirman que estas "pueden ser cumplidas o no", mientras los primeros "son mandatos de optimización (...) que pueden ser cumplidos en distinto grado, en la medida de lo posible". Añaden que las exigencias del artículo 485 del Código "plasman en plenitud el test de proporcionalidad, con sus tres subprincipios" ${ }^{\prime 18}$. En el mismo sentido se pronuncian los restantes promotores de la tutela en Chile ${ }^{19}$. Con la salvedad ya anotada respecto de un autor, la totalidad de sus promotores coinciden en que el criterio idóneo para afrontar la tensión entre los derechos fundamentales del trabajador y los del empleador es la versión principialista del TP.

\section{LAS EXIGENCIAS DEL TEST DE PROPORCIONALIDAD EN LA TUTELA LABORAL}

Veremos que la adhesión a la versión optimizadora también riñe con la interpretación sobre una de las exigencias del test. Los autores concuerdan en que el TP se estructura

\footnotetext{
10 Mella y Domínguez (2012) p. 192.

11 Melis (2011) p. 104: la tutela "contempla, expresamente, en el inciso tercero del nuevo artículo 485 (...) el principio de proporcionalidad”. También UGARTE (2009) pp. 73 y ss.

12 UGarte (2011a) p. 366: "Mientras las reglas se aplican mediante la subsunción, los principios se someten a deliberación, cálculo y balanceo"; GAMONAL (2008) pp. 42-45.

13 CaAmaño (2006) pp. 35 y 37. El TP es un modo de ponderar un derecho "con otros derechos o bienes constitucionalmente protegidos" como "la moral, el orden público y el bien común”, sin aludir a Alexy.

14 Contreras y Aguilar (2007) pp. 205-243; Gamonal (2008) pp. 11-40; Ugarte (2007) pp. 49-67; Melis (2011).

15 Rivers (2006) pp. 181 y ss., y Webber (2009) pp. 56 y ss. emplean esta terminología.

16 Alexy (2002); Alexy (2002b); Alexy (2003).

17 Gamonal (2008) p. 42.

18 Gamonal (2008) pp. 42 y 45.

19 Melis (2011) p. 104, acude a la distinción como base del TP. UGARTE (2009) p. 75, cita a Alexy para decir que el test no solo deriva de "la teoría de los principios" sino que esta implica el test.
} 
sobre una aplicación escalonada de al menos tres subprincipios: idoneidad o adecuación, necesidad (o necesariedad) y proporcionalidad en sentido estricto. La justificación para limitar un derecho fundamental (del trabajador) que arranca del ejercicio de otro derecho fundamental (del empleador), es necesario preguntarse si la referida restricción cumple cada una de estas tres exigencias ${ }^{20}$, por lo que si cualquiera de estos subprincipios no es sorteado, la conclusión es que la medida que restringe el derecho no satisface el test ${ }^{21}$.

La idoneidad examina la conexión racional entre la medida restrictiva del derecho del trabajador y el fin perseguido en el ejercicio de los derechos del empleador. La necesidad controla que la interferencia en el derecho del trabajador sea mínima dentro de las posibilidades, jurídicas y fácticas, que permiten al empleador satisfacer su interés. La proporcionalidad en sentido estricto busca equilibrar los beneficios que la medida adoptada por el empleador irroga con el daño padecido en el derecho afectado, para concluir en qué lado de la balanza se sitúa el mayor bien comparativo. Debe lograrse "un cierto equilibrio entre los beneficios que se obtienen por la protección del derecho, valor o fin que motiva la limitación del derecho fundamental y los perjuicios que derivan para el derecho que se ha visto limitado" 22 a fin de evaluar si "las ventajas que se obtienen mediante la intervención en el derecho fundamental deben compensar los sacrificios que esta implica para sus titulares y para la sociedad en general" 23 . Similar fórmula adopta el resto ${ }^{24}$. Esta exigencia se discierne, veremos, según la ley de la ponderación.

Algunos adhieren a una proporcionalidad en sentido estricto en clave alexiana, pero le incorporan la exigencia del respeto al contenido esencial de los derechos, exigido por el Código ${ }^{25}$ y también por la Constitución Política (“Constitución” o "CPR”). Gamonal añade a este subprincipio la exigencia de que con la medida restrictiva de los derechos fundamentales "no se afecte la esencia del derecho fundamental del trabajador", según el artículo 19 No 26 de la $\mathrm{CPR}^{26}$. Así, hay autores que en este punto se sitúan fuera de las coordenadas optimizadoras. Por otro lado, la generalidad no aborda la exigencia de legitimidad del fin, puesto que suelen darla por implícita en la idoneidad teleológica o bien la tratan como la primera de cuatro exigencias. La explicación reside en que tratándose de la tutela, los laboralistas no identifican el fin constitucionalmente legítimo con un fin de bien público sino con uno que emana del objeto perseguido por el ejercicio de los derechos de propiedad y libertad empresarial del empleador ${ }^{27}$.

20 Ugarte (2009) pp. 75-76; Melis (2011) pp. 108-109.

21 Melis (2011) p. 109, en cita a AleXy (2002b) pp. 27 y ss.

22 Carrizosa (2004) pp. 471-510; p. 503, citado por Ugarte (2011b) pp. 198 y 292.

23 Fórmula adoptada por Bernal (2002b) p. 36, seguidor de Alexy muy citado por los autores.

24 Caamaño (2006) p. 41; Melis (2001) p. 107; Mella y Domínguez (2012) pp. 207-208.

25 Mella y Domínguez (2012) p. 209, dicen que el contenido esencial "es parte de la proporcionalidad en sentido estricto, ligando tal criterio a la racionalidad de la medida (...) suponiendo por tanto la existencia de un núcleo irreductible, inaccesible a todo intento limitador".

26 Gamonal (2008) pp. 46 y 47.

27 Caamaño (2006) p. 24; Melis (2010) p. 109; Gamonal (2008) p. 45; Mella y Domínguez (2012) pp. 200203. Con todo, UGarte (2011b) p. 128 y UGarte (2009) p. 76, dice que tal fin busca proteger los derechos del empresario y de terceros, y la seguridad o integridad de los trabajadores o de los clientes, aunque para él no sea parte del test sino una condición previa a su empleo. 


\section{LOS DERECHOS DE LOS TRABAJADORES CARECEN DE UN CONTENIDO DEFINITIVO E}

\section{INVIOLABLE, LO QUE HACE INEVITABLE ACUDIR AL TEST}

En consonancia con la noción principialista, Ugarte señala que los derechos fundamentales poseen un contenido amplio e indeterminado "conformado por todo el espectro de normas y de posiciones jurídicas que sea posible relacionar semánticamente con el derecho tipificado en la Constitución". Es un contenido "prima facie" que "se lleva a cabo con criterios muy laxos y se fundamenta en el principio in dubio pro libertate" 28 . Esto se opone a la idea "dominante en nuestra cultura jurídica de un ámbito protegido estrecho de los derechos fundamentales", según la cual, "tienen un contenido definitivo fijado de antemano, o preformado, que cuenta desde el inicio con unas determinadas limitaciones" 29 .

Al ser "mandatos de optimización" 30 , los derechos pueden cumplirse gradualmente o "en la mayor medida posible". Esto lleva a afirmar que "la naturaleza de los principios implican el principio de proporcionalidad" 31 . No debe llamar la atención que se sostenga que la optimización entre los principios es inevitable conforme a la "ley de la ponderación", según la cual "cuanto mayor es el grado de afectación de uno de los derechos en juego, tanto mayor debe ser la importancia de la satisfacción del otro" ${ }^{32}$. Esta labor ponderativa se traduce en discernir el grado de interferencia del derecho del trabajador (v.gr. intimidad) con el grado de satisfacción del fin buscado ( $v$.gr. seguridad de la empresa y trabajadores) con el acto del empleador. La afectación del derecho puede ser leve, moderada o seria, y lo mismo ocurre con el grado de satisfacción del fin o derecho en contraposición, que puede ser indiferente, importante o muy importante.

Según la ley de la ponderación, los principios gozan del mismo peso in abstracto, esto es, antes de emplear el TP, por lo que si se estima que la interferencia en el derecho es "moderada", mientras que la satisfacción del principio contrario es "muy importante", el acto examinado sería conforme al test ${ }^{33}$. Consecuencialmente, la menor (leve) afectación a la honra del trabajador podría verse compensada por la mayor (importante) satisfacción del fin asociado al ejercicio de los derechos del empleador (seguridad de la empresa), resolviéndose la proporcionalidad en sentido estricto (y, por tanto el test) a favor del derecho del empleador. Los autores adhieren a estas categorías de atribución de pesos que proceden de la distinción entre principios y reglas ${ }^{34}$.

Prácticamente todos quienes promueven la tutela asumen que los derechos son principios optimizables, por lo que, colisionan inevitablemente debiendo afrontarse la resolución del conflicto mediante el TP, lo que postula el sacrificio de un derecho en beneficio de otro derecho que sale airoso por haberse estimado que gozó de mayor peso, atendido la ley de la ponderación. Así, el contenido del derecho fundamental queda determinado con posterioridad al empleo del test.

\footnotetext{
28 Bernal (2007) p. 310, citado por Ugarte (2009) pp. 52-53.

29 UGARTE (2009) p. 61.

30 Alexy (2002) p. 388.

31 Alexy (2002) pp. 47-48, p. 57 y p. 66.

32 Alexy (2002) p. 66, citado por UGarte (2009) p. 74.

33 AleXy (2002) p. 102, p. 106, pp. 410 y ss.

34 Gamonal (2008); Mella y Domínguez (2012) p. 184; Melis (2010) pp. 89 y ss. Una salvedad es CaAmaño (2006) quien no obstante no adherir a Alexy ni a la distinción principialista, adopta en p. 41, una noción de la proporcionalidad en sentido estricto que es formulada por Alexy.
} 
4. El CONTENido ESENCiAL De los DEREChos ES UNA FRONTERA DEL PROCESO PONDERATIVO

Algunos de quienes proponen la versión principialista del TP en la tutela admiten que su aplicación debe respetar el contenido esencial de los derechos, de conformidad con la hipótesis establecida en el inciso tercero del artículo 485 del Código, que dispone que se entenderán vulnerados los derechos fundamentales del trabajador cuando el ejercicio de las facultades del empleador limite su "pleno ejercicio" "sin justificación suficiente, en forma arbitraria o desproporcionada, o sin respeto a su contenido esencial" 35 . Junto con concebir el test como un instrumento para ponderar derechos fundamentales o bienes concebidos como principios, reconocen el contenido esencial de los derechos como una barrera que detiene el test en el entendido que tal contenido medular supone la "existencia de un núcleo irreductible, inaccesible a todo intento limitador" 36 . Si bien Ugarte descartó en un principio el carácter inviolable del contenido esencial al sostener que este "nunca es definitivo o inderrotable ${ }^{37}$, últimamente ha admitido que los derechos fundamentales pueden gozar en su contenido de algún aspecto inviolable ${ }^{38}$.

En este punto, los autores se apartan un tanto del ideario alexiano conforme al cual los derechos fundamentales, al ser principios, constituyen un elemento disponible dentro de la ecuación ponderativa. Esto no solo contraviene la premisa, ya anotada, según la cual no cabe reconocer en los derechos un contenido definitivo fijado de antemano sino que al mismo Alexy, quien ha dicho que "las posiciones de los individuos (...) pueden ser eliminadas o restringidas en aras de bienes colectivos"39, al punto de afirmar que "no puede ser sostenido en el derecho constitucional (...) la convicción de que debe haber derechos que en las más extremas circunstancias no sean sobrepasados" ${ }^{\prime 2}$. La coherencia entre adherir a la noción principialista de los derechos (y del test) y abrazar al mismo tiempo aspectos que constriñen su alcance optimizador ha sido abordado en otros trabajos por lo que no volveremos sobre ello ${ }^{41}$.

\section{PROBLEMAS DE LA VERSIÓN PRINCIPIALISTA DEL TEST EN LA TUTELA LABORAL}

1. El intento de atribuir al artículo 485 del Código la adopción de una MODALIDAD DEL TEST DE PROPORCIONALIDAD

Hemos visto que la mayoría de los promotores de la tutela concuerdan en que el artículo 485 del Código consagra una precisa versión del TP, conforme a la cual el exce-

35 Código del Trabajo, artículo 485, inciso 3.

36 CAAMAÑo (2006) p. 37: la limitación a los derechos del trabajador por el empleador "solo resultará ajustada si está justificada constitucionalmente a través del juicio de proporcionalidad y si no afecta el contenido esencial del derecho"; Gamonal (2008) pp. 46-47 y Melis (2010) pp. 102-104; Mella y Domínguez (2012) p. 209.

37 UGARTE (2011b) p. 279.

38 Ugarte (2011b) p. 256.

39 Alexy (1994) p. 207.

40 Alexy (2002) p. 196.

41 Covarrubias (2015) pp. 261-287. 
so o desproporción del acto del empleador dependerá del resultado de ponderar entre las ventajas de la medida adoptada por él y la interferencia padecida por el trabajador en sus derechos fundamentales, sin concebirse anticipadamente ni en términos generales alguna frontera que sea infranqueable a la incursión ponderativa. No solo diremos que la fórmula establecida por el Código difícilmente establece TP alguno, sino que dificulta especialmente el impulso y la aplicación de su modalidad principialista. Algunos críticos de la tutela ya se habían adelantado en señalar que el artículo 485 únicamente prevé causales diferenciadas de afectación a los derechos fundamentales del trabajador, que no pueden ser reconducidas a una causal más amplia, como sería la infracción a un test ${ }^{42}$.

Del análisis singular de la exigencia de que los derechos fundamentales del trabajador no sean limitados "en forma (...) desproporcionada" no se sigue nada similar a la adopción por el legislador de un estándar como el TP. Si bien dicha exigencia, aisladamente considerada, podría cobijar varias interpretaciones sobre su alcance en el derecho nacional ${ }^{43}$ y comparado ${ }^{44}$, creemos que la posibilidad de dar cabida a la modalidad principialista del test se dificulta sobremanera también por otras consideraciones, a saber, al examinar otros aspectos de la normativa.

La historia fidedigna de la ley 20.087, que incorporó el procedimiento de tutela, no aporta antecedente alguno del cual podría desprenderse la necesidad de interpretar los requisitos del inciso tercero del artículo 485 del Código conforme con la ponderación principialista, ni mucho menos todavía, con alguna modalidad del $\mathrm{TP}^{45}$. En tercer lugar, el artículo 485 exige que las limitaciones a los derechos del trabajador respeten su contenido esencial, con lo cual el legislador pone, en algún grado, un coto anticipado a cualquier método ponderativo para impedir que sean sacrificados ciertos aspectos inviolables del contenido de los derechos fundamentales ${ }^{46}$.

En cuarto término, creemos que la prohibición de que las limitaciones a los derechos sean "sin justificación suficiente" alude a un requisito mínimo, que exige que la medida tenga fundamento y/o justificación en el sentido que lo carente de fundamentación es por sí solo arbitrario ${ }^{47}$. El carácter "suficiente" de la justificación es más bien redundante, pues

42 Ferrada (2011) p. 105.

43 Nogueira (2010) pp. 403 y ss. y Arnold et al. (2012) p. 96.

44 El enfoque de Clayton y Tomlinson (2009) p. 298; Craig (2003) p. 662, busca evitar que del acto se sigan "cargas o daños excesivos" para los regulados, donde el resultado "excesivo" se impide exigiendo la "intervención mínima o el medio menos lesivo”. Otros, Lester y Pannick (2004) p. 89 y Wade y Forsyth (2004) p. 366, la ven como una regla de "justo equilibrio" que identifica lo proporcionado como la medida que se encontraba dentro del rango de cursos de acción que podían razonablemente ser seguidos”. Para VAN DER WaLT (1999) p. 135; Cohn (2010); Rivers (2006) pp. 176 y ss., la determinación del exceso depende del resultado de la ponderación entre costos y beneficios pero admiten que esta operación llega hasta donde se afecte el contenido esencial de los derechos o algún aspecto inviolable de estos como la dignidad humana. En Covarrubias (2013) y Covarrubias (2014) pp. 77-184, mostramos casos en que la Cámara de los Lores, el Tribunal Constitucional alemán y el Tribunal Europeo de Derechos Humanos no acude al test optimizador. Al respecto: CoHn (2010); Schwabe (2009) pp. 60, 223, 390, 126; Susnjar (2010) p. 136, y AleXander (1996) p. 134; Christoffersen (2009) p. 32; STEIN (2005) pp. 729-731; López EsCarcena (2014) pp. 60-63.

45 Historia de la Ley 20.087, de 2006.

46 Aldunate (2008) pp. 261-264.

47 FERnÁNdeZ (1991) pp. 106-107. 
lo "suficiente" es propio del discernimiento de lo "arbitrario o desproporcionado", que en esta disposición es parte del segundo requisito establecido, por lo que una lectura plausible sería aquella que entiende por "justificación suficiente" aquella medida que tiene su fundamento en las potestades constitucionales/legales del empleador ${ }^{48}$.

Al exigirse que los derechos fundamentales no sean limitados "en forma arbitraria o desproporcionada”, el legislador tampoco favorece una lectura optimizadora del artículo 485, sino más bien apunta a desterrar el ejercicio abusivo de un poder legalmente conferido ${ }^{49}$, pero al estar ambos enunciados bajo la conjunción disyuntiva "o", creemos que la exclusión de la arbitrariedad no podría ser equiparada a la falta de proporcionalidad. En efecto, bajo la interpretación más habitual, arbitrario es lo carente de fundamento racional en la norma, la justicia o la lógica ${ }^{50}$. Esto sitúa la arbitrariedad un peldaño más alto que la mera exigencia de fundamentación ( $v$. gr. la afirmación del empleador de que la instalación de cámaras emana de su derecho de propiedad) y uno más abajo que la proporcionalidad en una de sus formas menos intensas, como sería por ejemplo la exigencia de conexión racional entre medio y fin.

La exclusión de la arbitrariedad no solo supone la motivación legal del acto (requisito, que vimos, viene dado por la necesidad de justificación) sino que tal conducta sea plausible en justicia y lógica $(v . g r$. la instalación de cámaras busca proteger a los trabajadores y evitar daños a la empresa). Por su parte, la exigencia de que las medidas adoptadas por el empleador no sean "desproporcionadas" apunta a responder si las cámaras son idóneas para dar protección a los trabajadores y evitar los aludidos daños.

En síntesis, las dos primeras posibilidades de infracción a los derechos fundamentales del trabajador -legalidad y arbitrariedad (que también comprende la exigencia de proporcionalidad como conexión racional entre medios y fines) - poco o nada ayudan a la afirmación de que el inciso tercero del artículo 485 establecería la aplicación de un TP, con reglas copulativas, aunque la arbitrariedad pueda vincularse parcialmente con algún requisito del test. Ahora bien, al examinarse la tercera forma de infracción -el contenido esencial- es claro que el TP queda bastante desencajado ${ }^{51}$, al menos bajo la versión a la que adhiere buena parte de los laboralistas que en Chile promueven el test.

\section{LA DifiCULTOSA ARTICULACIÓN ENTRE PROMOVER LOS DERECHOS FUNDAMENTALES COMO PRINCIPIOS OPTIMIZABLeS Y EL ARTí́CUlo 485 DEL Código del Trabajo}

No pretendemos efectuar una crítica meramente teórica a la distinción entre principios y reglas ${ }^{52}$, sino en problematizar -particularmente de cara a los fines de la tutela y de su configuración en el Código- la idea de que las normas que expresan derechos fundamentales son principios. Lo primero que se sigue de la distinción, acogida por Alexy y sus

\footnotetext{
48 Ferrada (2011) p. 108.

49 Ferrada (2011) p. 108; Fuentes Olmos (2012) p. 154

50 Soto Kloss (2010) p. 369; Cassagne (2008) pp. 1-2.

51 Paredes (2015) p. 220.

52 Creemos que es posible admitir la razonabilidad de la distinción sin necesariamente adherir a la idea de que los derechos fundamentales son principios o deben ser tratados como tales.
} 
seguidores, es que no hay derechos absolutos o aspectos inviolables en los derechos que no son absolutos, en el entendido que no puede ser sobrepasados bajo ninguna circunstancia, de modo que tampoco pueden ser justificadamente infringidos, debiendo ser cumplidos sin excepción ${ }^{53}$. En vistas al resguardo de los derechos del trabajador es complejo concebirlos como principios al modo de Alexy ${ }^{54}$, sea porque hay unos pocos derechos fundamentales absolutos, sea porque varios de los derechos (que no son absolutos) poseen un aspecto medular que no es susceptible de ser sacrificado por vía de optimización ponderativa con otros derechos o bienes ${ }^{55}$. Veremos aspectos de derechos fundamentales cuya tutela difícilmente podría quedar sujeta a la lógica principialista.

Del reconocimiento de que en el Derecho constitucional hay una zona de penumbra $^{56}$ o que los derechos fundamentales poseen una textura abierta y maleable ${ }^{57}$, no se sigue que todo el espectro del contenido de todos los derechos sea igualmente dúctil a la incursión ponderativa con otros derechos o bienes. Hay partidarios de la textura abierta o de los derechos como principios, en sentido amplio, que admiten (con matices que no es del caso precisar) que hay bienes o derechos que deben quedar excluidos de la ponderación utilitarista $^{58}$. Otros dicen que la distinción de principios y reglas no obedece a una cuestión cualitativa sino de grado que se especifica por la mayor o menor generalidad de las normas ${ }^{59}$. El mismo Alexy, con posterioridad a su Teoría General, ha moderado el sentido fuerte de la distinción, al afirmar que hay un sentido amplio de los derechos fundamentales, donde son formulados como principios y otro estricto, donde son observados "como regla" ${ }^{60}$. Para Alexy, ya no se podría afirmar tan categóricamente que las normas que contienen derechos fundamentales son siempre principios ${ }^{61}$, aspecto en el que sus seguidores de la tutela no han reparado.

Con todo, lo crucial no es la amplitud del enunciado de los derechos fundamentales, que brindan flexibilidad en su aplicación a las distintas situaciones que difícilmente pueden ser previstas por el legislador ${ }^{62}$. Lo complejo es atribuir a los derechos el carácter de principios optimizables, lo cual no solo incide en la comprensión de la naturaleza jurídica de

53 GeWIRTh (1984) p. 91.

54 Guastini (1999) pp. 142-178, observa las dificultades para distinguir entre principios y reglas, dada la heterogeneidad de criterios utilizados y las dificultades para reconducir todos los elementos calificados como "principios" a una concepción unitaria. Asimismo, Susnjar (2010) pp. 282-295.

55 Con todo, admite que hay principios -la prohibición de la injusticia extrema- en virtud del cual la tortura, esclavitud o discriminación racional quedarían extramuros de cualquier método ponderativo, siguiendo la idea de que la injusticia extrema no es derecho. La referencia a la esclavitud en AleXY (1989) pp. 137-138.

56 Hart (1994) pp. 14-15.

57 Zagrebelsky (1995).

58 Waldron (1993) p. 30; Habermas (2001) p. 278. Sobre Zagrebelsky, véase Lariguet (2005) pp. 67-74.

59 RAZ (1975) p. 49.

60 Alexy (2003a) pp. 131-132: "Hay dos formulaciones de los derechos fundamentales: una es estrecha y estricta, la segunda, es amplia y comprensiva. La primera puede ser denominada una formulación como regla, la segunda, formulación como principios".

${ }_{61}$ Borowsky (2000) pp. 29-56, seguidor de Alexy, ha admitido que los principios no fundamentan la ponderación (proporcionalidad en sentido estricto) sino que valores externos por lo que "es posible afirmar que la decisión antes que adoptada es estructurada por la teoría de los principios".

62 Gamonal (2015) pp. 68 y 129. 
la CPR y de los derechos fundamentales ${ }^{63}$, sino que pone en entredicho el reconocimiento de un contenido inviolable en aquellos y, a la postre, debilita la efectividad de la tutela con miras a sus fines protectores. Hay aspectos de los derechos fundamentales cuyos mandatos calzan más bien con la idea de reglas, pues ordenan algo en términos específicos y categóri$\cos (v . g r$., no ser discriminado por color de piel) o contienen aspectos que difícilmente son ponderables en virtud de los derechos de un tercero que no sea un tercero imparcial ( $v . g r$, intimidad fisiológica o corporal). Para Alexy, en cambio, no hay otro contenido que aquel constituido por el empleo del test ${ }^{64}$.

Lo dicho evidencia la problemática entre promover un TP principialista y aplicar el artículo 485 del Código que le pone un límite (con lo cual el principialismo deja de ser lo que es) a menos que matice su posición o se explicite la adhesión a una versión del test que admita la existencia de aspectos infranqueables en el ámbito protegido por los derechos fundamentales, con lo cual ya no puede hablarse de un test optimizador o de raigambre alexiana. Ni una ni otra observación ha sido efectuada por los autores.

En segundo lugar, los catálogos de derechos fundamentales reconocidos en constituciones o en convenios internacionales contienen unos pocos derechos categóricos o algunos aspectos de estos que difícilmente son susceptibles de optimización. La prohibición de la esclavitud y de la aplicación de todo apremio ilegítimo son mandatos perentorios que no se condicen con la idea de principios. En el derecho internacional, la garantía contra la tortura y el derecho al debido proceso son ejemplos clásicos de mandatos categóricos. Estas provisiones, se afirma, conllevan la obligación de asegurar que cualquier medida estatal no infrinja su carácter absoluto. Ni siquiera la concurrencia de circunstancias excepcionales como los Estados de Excepción o un conflicto armado podría suspender dichas exigencias $^{65}$.

Hay derechos fundamentales que sin ser absolutos contienen aspectos inviolables frente a exigencias emanadas de otros derechos o bienes con los que se ven confrontados. Pensemos en la esfera sensible de la libertad religiosa o de la intimidad. Algunos constatan la adopción jurisprudencial de un contenido esencial en términos absolutos al producirse situaciones en las que "[c]iertos aspectos de derechos relativos pueden recibir protección bajo un derecho absoluto y los derechos relativos pueden constituir un contenido medular absoluto que no se encuentra sujeto a limitación en ninguna circunstancia" ${ }^{66}$. Lo que se acaba de decir en relación al Tribunal Europeo de DD.HH. también se observa en otras jurisdicciones que han rehuido acudir al TP si está en riesgo el núcleo de un derecho fun-

63 Habermas (2001) p. 329: "los derechos fundamentales están formados conforme al modelo de normas obligatorias de acción y no conforme al modelo de bienes apetecibles". Un interesante enfoque en MARSHALL (2007) pp. 207-228.

64 AleXY (2002) pp. 192-196.

65 BAŞAK (2007) p. 258. La Convención Europea de DD.HH. establece cuatro derechos en términos incondicionados: prohibición de tortura o un trato o castigo inhumano o degradante (art 3); prohibición de esclavitud o servidumbre (Art 4.1); prohibición de ser condenado por una conducta que al momento de cometerse no constituya una infracción según el derecho nacional o internacional (Art 7.1); Prohibición de imponer una pena más grave que la aplicable al momento de cometerse la infracción (Art 7.1).

66 Christoffersen (2009) p. 163; Barak (2012) p. 27, menciona la prohibición de la esclavitud como un derecho absoluto, y pp. 497-98, al referirse a la relación entre el "núcleo" del derecho y el exceso del TP. 
damental ${ }^{67}$, entre otros casos comparados ${ }^{68}$, en que la adjudicación constitucional ha encontrado una frontera en el contenido esencial de los derechos, en aspectos inviolables de estos o en la dignidad humana.

Existen motivos adicionales para pensar que calificar a los derechos fundamentales como mandatos optimizables es reduccionista. En las constituciones contemporáneas no solo hay normas que podrían ser optimizables, sino también numerosas que son más bien defensas de otro tipo, tales como permisiones positivas (autonomía contractual), otras que establecen la incompetencia de una autoridad de prohibir una acción (censura previa) o que prohíben a todos la ejecución de ciertas conductas (torturas) o interferir con el ejercicio de un derecho (sufragio) ${ }^{69}$.

Lo dicho toca especialmente a los derechos fundamentales del trabajador, pues varios de estos se resisten a ser encasillados como principios, lo cual es admitido incluso por varios promotores de la tutela, que conceden que el Código prevé hipótesis "que pueden resolverse sin necesidad de acudir a la noción de colisión de derechos fundamentales" en las que

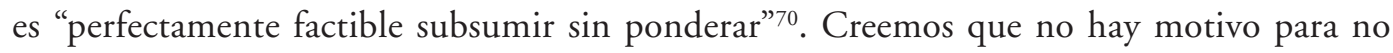
hacer extensivo a la generalidad lo que para algunos solo es predicable respecto de prácticas antisindicales/desleales, la discriminación salarial por razón de sexo o por "represalias ejercidas en contra de trabajadores, en razón o como consecuencia de la labor fiscalizadora de la Dirección del Trabajo o por el ejercicio de acciones judiciales"71.

Hay infracciones tan evidentes y sensibles a los derechos fundamentales, que su resguardo no puede quedar sujeto al "peso" o "valor" relativo del derecho o bien que aparece en contraposición, por lo que su abordaje ha de ser afrontado como reglas antes que como mandatos optimizables. Por ejemplo, no es necesario acudir a ponderación alguna para brindar tutela al derecho a la honra del trabajador cuyas remuneraciones han sido descontadas por el empleador, sin investigación ni procedimiento legal alguno, fundado en su eventual responsabilidad por la pérdida de dinero a cargo de la trabajadora ${ }^{72}$. Tampoco pueden ser optimizables ciertas expresiones que serán siempre denigrantes o vejatorias, con prescindencia del derecho invocado en contrario ${ }^{73}$.

Más adelante veremos otros casos, reales y ficticios, que muestran que la generalidad de los derechos fundamentales garantizados por la tutela no se ajustan al molde principia-

\footnotetext{
67 GRIMM (2007) p. 386, al referirse a la disposición constitucional de la Ley Fundamental de Bonn en cuanto a que "ninguna limitación puede afectar el contenido esencial de un derecho fundamental"; ÖRÜCÜ (1986) pp. 45-53, quien alude al "núcleo" de los derechos en Alemania y Turquía.

68 Covarrubias (2013) p. 492, muestra casos de la Cámara de los Lores que excluyen o minimizan el TP si un derecho está formulado en términos absolutos. Sobre lo mismo en Sudáfrica, Petersen (2013) pp. 1-23.

69 Guibourg (2013) pp. 76-77. (El ejemplo de la tortura es mío).

70 Mella y Domínguez (2012) p. 199. Respecto de las prácticas antisindicales y prácticas desleales y también a la discriminación salarial por razón de género (artículo 62 bis). Debe considerarse lo dicho por CaAmaño (2006) pp. 35 y 37, y UGARTE (2009) p. 37 sobre la garantía de indemnidad.

71 Código del Trabajo, artículo 485, inciso tercero, oración final: "En igual sentido se entenderán las represalias ejercidas en contra de trabajadores, en razón o como consecuencia de la labor fiscalizadora de la Dirección del Trabajo o por el ejercicio de acciones judiciales”.

72 GARRIDO CON FOTOGRAFICA FULLCOLOR LTDA (2010)

73 InSPECCIÓN PRoVINCIAL del TRABajo CON ASOCIACIÓN INDÍGENA NEWENTULEAIN (2014).
} 
lista, pues hay situaciones de vulneración a aquellos cuyo resguardo exige la subsunción o delimitación, sin acudir a optimizarlos con los derechos del empleador.

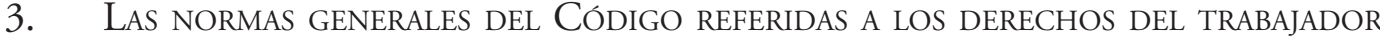

TAMPOCO SE CONDICEN CON LA VERSIÓN PRINCIPIALISTA DEL TEST

Creemos que la afirmación de que el artículo 485 adopta una modalidad optimizadora de ponderación entre los derechos del trabajador y las potestades del empleador no solo no se desprende de las restantes disposiciones del Código que abordan la materia, sino que tal predicamento tampoco es conteste con el modo en que tales normas están formuladas. Así, el artículo 2 prohíbe, sin excepción alguna, ciertos actos de discriminación ${ }^{74}$. Por su parte, el artículo $5^{\circ}$ dispone que "[e]l ejercicio de las facultades que la ley le reconoce al empleador, tiene como límite el respeto a las garantías constitucionales de los trabajadores”. Estas disposiciones, junto a otras ${ }^{75}$, acuden a expresiones perentorias que representan un lenguaje de esferas intocables que se aviene más con las reglas que con los principios ${ }^{76}$, con la subsunción antes que la ponderación.

En segundo lugar, el artículo 154 dispone que "las obligaciones y prohibiciones a que estén sujetos los trabajadores", así como "toda medida de control, solo podrá efectuarse por medios idóneos y concordantes con la naturaleza de la relación laboral”77. Además del carácter impersonal en su aplicación, la norma exige que la medida sea apta para el fin, lo cual alude a una proporcionalidad circunscrita a la idoneidad que corresponde a uno de los subprincipios del test. Ahora bien, cuando la disposición añade que todas estas garantías son "para respetar la dignidad del trabajador", lo que hace es poner un obstáculo insalvable a la posibilidad de instalar cámaras personalizadas, que no obstante ser idóneas y concordantes con la naturaleza del trabajo, serían de todos modos ilegítimas al comprometer un aspecto de la intimidad vinculada a la dignidad del trabajador. Una vez más, el verbo pertinente parece ser subsumir antes que ponderar y dentro del abanico ponderativo, la opción optimizadora no es sino la más lejana de todas las disponibles.

Con la salvedad de los dictámenes de la Dirección del Trabajo, el contexto jurídico era el menos propicio para inclinarse por una forma de adjudicar derechos de raíz prin-

\footnotetext{
74 Código del Trabajo, artículo 2 inciso $3^{\circ}$ a 5º prohíbe, sin excepción, los actos de discriminación motivados por "raza, color, sexo, edad, estado civil, sindicación, religión, opinión política, nacionalidad, ascendencia nacional u origen social, que tengan por objeto anular o alterar la igualdad de oportunidades o de trato en el empleo y la ocupación” (salvo las “calificaciones para un empleo determinado").

75 Código del Trabajo, artículo 492, prevé que el juez suspenderá el acto impugnado "cuando aparezca (...) que se trata de lesiones de especial gravedad o cuando la vulneración (...) pueda causar efectos irreversibles”. Sobre esta disposición, volveremos más adelante.

76 Mella y Domínguez (2012) p. 187, dicen que las normas vinculantes de la relación laboral impuestas por el empleador, están "limitadas por los derechos fundamentales, constituyendo un núcleo inalcanzable por el poder de dirección y mando, integrado por la dignidad, libertad e intimidad del trabajador”.

77 Código del Trabajo, artículo 154, inciso final: "Las obligaciones y prohibiciones a que hace referencia el número 5 de este artículo [sobre las "obligaciones y prohibiciones a que estén sujetos los trabajadores"], y, en general, toda medida de control, solo podrán efectuarse por medios idóneos y concordantes con la naturaleza de la relación laboral y, en todo caso, su aplicación deberá ser general, garantizándose la impersonalidad de la medida, para respetar la dignidad del trabajador".
} 
cipialista. La falta de sustento legislativo, la defectuosa articulación del artículo 485, la aplicación histórica prevalente de la subsunción como criterio de adjudicar derechos exigía al menos una explicación de envergadura que no ha ocurrido. Es ilustrativo que uno de los autores que se ha empeñado en calzar las reglas del test bajo las formas de infracción del inciso tercero del artículo 485 diga que el juicio de necesidad alude a que la medida que vulnera el derecho no se ejerza "sin justificación suficiente"78. El autor no solo interpreta la necesidad de un modo que no tiene que ver con versión alguna de este subprincipio, sino que además pasa por alto, sin explicación, una regla legal como es la del contenido esencial.

El esfuerzo doctrinario no solo altera el sentido y alcance del artículo 485 del Código para ajustarlo a la concepción optimizadora el test, sino que pasa por alto que esta modalidad es, comparativamente, la menos conciliable con los requisitos establecidos por el legislador, en particular con la exigencia del contenido esencial, pues esta desconoce el supuesto sustentado por algunos promotores de la tutela, de que los derechos fundamentales son del todo derrotables, dado que son normas de principios.

\section{El contenido esencial de los derechos tampoco se aViene con la Versión PRINCIPIALISTA DEL TEST, PUES OBLIGA A SUBSUMIR}

La versión optimizadora del TP no solo no calza con las reglas legales de la tutela laboral, sino que es incompatible con el requisito del artículo 485, que exige que las limitaciones impuestas a los derechos fundamentales del trabajador han de respetar su contenido esencial. Si bien varios de los promotores de la modalidad alexiana del test han intentado conciliar su adhesión al principialismo con la exigencia del contenido esencial, nada o poco dicen, con la salvedad ya anotada, en cuanto a que la noción de principios es antitética con la idea de un contenido fijo y previo en los derechos fundamentales.

En efecto, algunos autores advierten hipótesis en las que las medidas adoptadas por el empleador consistirían en una ilegalidad (escuchas telefónicas) ${ }^{79}$ o en una medida que afecte el contenido esencial del derecho fundamental ${ }^{80}$, conductas que el juez estaría obligado a reprimir sin ponderación no proporcionalidad de por medio.

No podemos sino coincidir que en tales casos no hay que ponderar, pero se echa en menos un reconocimiento más explícito de que tales supuestos contradicen una aplicación coherente con la versión del test que desconoce la existencia de algún aspecto inviolable en los derechos fundamentales. Según esta concepción optimizadora, podría darse que en un caso concreto el desplazamiento de un derecho a favor de otro no fuere total, pero no sería inconsistente que de la aplicación del TP se siguiera una capitulación total de un derecho a favor de otro con el que aparece confrontado.

Vimos ya que entre la versión principialista del TP y la aceptación de la garantía que protege el contenido esencial de los derechos hay un abismo insalvable: para aquella no es

\footnotetext{
Mella y Domínguez (2012) p. 195.

79 UGarte (2009) pp. 62-63.

80 CaAmaño (2006) pp. 35 y 37. Ugarte (2009) p. 37: “(...) a diferencia de lo que ocurre con los derechos fundamentales estructurados como principios, la garantía de indemnidad no debe ponderarse ni balancearse con otros derechos, de modo tal que nunca hay represalias "justificadas o proporcionadas".
} 
permisible concebir in abstracto ni anticipadamente un límite inviolable en el contenido de los derechos, motivo por el cual tampoco tendría sentido reconocer un contenido esencial en ellos. Pues bien, para quienes entienden que en estos hay una barrera infranqueable que representa su contenido esencial, esta solo cobra operatividad una vez que se ha vislumbrado a priori el contenido medular de un derecho. Difícilmente el contenido nuclear de la vida privada puede operar como límite si el intérprete no tiene una idea anticipada acerca de qué es aquello que está en juego, esto es, acerca de cuáles aspectos de tal derecho se estiman inviolables en el caso concreto, razón por la cual dicha esfera se encuentra fuera del alcance ponderativo.

De las opciones de adjudicación más extendidas, con la salvedad de la jerarquización, la versión optimizadora es la única que derechamente excluye el reconocimiento efectivo del contenido esencial, pues conforme a ella el contenido del derecho fundamental solo puede ser determinado con posterioridad al empleo del test, incluido su total sacrificio, mientras que para las restantes aproximaciones la desproporción del acto puede verificarse, ya sea, sin utilizar el TP, ya sea, acudiendo a este pero con ciertos resguardos, como es el caso cuando el contenido medular del derecho en juego opera como una frontera infranqueable de la ponderación ${ }^{81}$, sea que el aspecto inderrotable del derecho sea absoluto o parcial. Si los derechos son del todo sacrificables no tiene sentido reconocer un contenido inviolable en ellos, a menos que medie una explicación coherente sobre el alcance con el que operaría el TP ${ }^{82}$.

En fin, el contenido esencial es inconsistente con los derechos entendidos como principios, pues obliga a subsumir y, por tanto, excluye con análoga intensidad la ponderación, pues no es posible resguardar la esfera inviolable de un derecho sin una idea previa y anticipada acerca del contenido definitivo y no negociable de lo que ello implica.

\section{La SUBSUNCIÓN ES IMPOSTERGABLE NO SOLO EN CASOS CALIFICADOS SINO EN LA \\ GENERALIDAD DE SITUACIONES DE AFECTACIÓN A LOS DERECHOS FUNDAMENTALES DEL TRABAJADOR}

Se ha visto que el Código prevé hipótesis - prácticas desleales/antisindicales, represalias- en que se admite que cabe "subsumir sin ponderar" ${ }^{3}$. Igual reconocimiento hacen los tribunales en la garantía de indemnidad, donde "estamos frente a una regla y no a un principio, por lo que no debe acudirse al juicio de proporcionalidad" ${ }^{4}$. El motivo se funda en que "nunca hay represalias "justificadas o proporcionadas"” 85 . Con un alcance más general se afirma que tampoco cabe ponderar si la acción del empleador es ilegal, pues "el legislador ya ha efectuado una verdadera ponderación legal mediante las reglas dictadas" 86 , por ejem-

81 En Covarrubias (2014) pp. 163-237 y Covarrubias (2013) pp. 470-501, hemos visto que la Corte Europea de DD.HH., la Cámara de los Lores y el TC alemán ha empleado estas versiones no optimizadoras del test.

82 Corresponde al esfuerzo intentado por algunos autores que promueven versiones moderadas del TP.

83 Mella y Domínguez (2012) p. 199. Contra: Palomo (2007) p. 63: dice que la indemnidad podría ser estimada un principio si se entendiera como manifestación del derecho a la tutela jurisdiccional efectiva.

84 MaCAYA CON CLÍNICA DENTAL CUMBRE SUR S.A. (2014) c. 8º por ejemplo.

85 CaAmaño (2006) p. 35, 37. Ugarte (2009) p. 37.

86 Ugarte (2009) p. 63. 
plo, la escucha telefónica que infringiría el artículo 161-A del Código Penal. El otro caso sería cuando la ley resuelve la controversia, lo que ocurriría en el artículo 154, inciso final del Código ${ }^{87}$.

Observamos que las razones que justifican desplazar el uso del TP en las situaciones expuestas son análogas a las que sustentan que la subsunción es inexorable en la generalidad de los casos y no solo en las calificadas hipótesis ya aludidas, por lo que estimamos que el Código ordena subsumir no solo frente a infracciones al contenido esencial de los derechos (artículo 485, inc. 3) sino que en todos los casos que produzcan efectos irreversibles en los derechos del trabajador (artículo 492). Este supuesto expande el espectro para la subsunción (y la consecuencial declinación del test principialista) bastante más allá de las hipótesis admitidas por los autores.

Hemos dicho que difícilmente puede discernirse si una medida adoptada por el empleador afecta el contenido de su derecho si no tenemos una representación previa acerca de lo que el derecho en cuestión deja adentro y deja afuera de su resguardo. Sin tal operación subsuntiva a priori es imposible determinar luego si un derecho fundamental, por ejemplo, la honra del trabajador ha sido menoscabado con ocasión de un despido que ha ido acompañado de agresiones verbales. Desde esta perspectiva, la subsunción es siempre inevitable, al menos en algún grado o fase ${ }^{88}$, lo cual no solo contraviene los supuestos del test optimizador sino que hace innecesario acudir a él ${ }^{89}$, aunque podría ser compatible la subsunción con versiones no optimizadoras del test.

Lo dicho da cuenta que hay un sinnúmero de infracciones a los derechos fundamentales, más allá de los acotados casos aludidos, cuya tutela no depende de la fortaleza del derecho, interés o fin invocado en contrario, sino que de la sola determinación acerca de si ha tenido o no lugar dicha vulneración y si esta es imputable al empleador, con prescindencia de si los actos de este afectan el contenido esencial del derecho, impiden su ejercicio o generan un efecto irreversible para su titular.

Así pues, en tercer lugar, la razón que lleva a subsumir frente a represalias es la misma que asiste la necesidad de extenderlo a un sinnúmero de casos graves que pueden afectar a la generalidad de los derechos del trabajador. Esta afirmación es respaldada por los artículos 492 y 485 del Código. Mientras el primero ordena suspender el acto impugnado "cuando aparezca (...) que se trata de lesiones de especial gravedad o cuando la vulneración (...) pueda causar efectos irreversibles"90, la segunda norma también hace inevitable subsumir cuando ha de discernirse si el contenido esencial ha sido afectado, lo cual, vimos, es imposible sin una idea previa de qué es aquello que está en juego y cuyo sacrificio debe ser evitado o al menos acotado. Así como no puede haber una represalia proporcionada, hay ciertas

\footnotetext{
87 Gamonal (2015) p. 68.

88 García Amado (2014), afirma que la subsunción es inevitable aun si se quiere aplicar el test.

89 Si bien excedería el objeto de este trabajo referirme a casos donde la aplicación del test puede genuinamente proteger los derechos fundamentales del trabajador, cabe señalar que el TC alemán ha mostrado que es compatible el uso de la ponderación y del test de proporcionalidad con la subsunción o con aspectos del derecho -contenido esencial o dignidad humana- que paralizan el alcance que podría tener un test no principialista.

90 Código del Trabajo, artículo 492.
} 
conductas que bajo ningún respecto pueden estimarse justificadas, como sería el caso de expresiones denigrantes respecto de una trabajadora ${ }^{91}$.

Las hipótesis de subsunción sin ponderación no quedan circunscritas únicamente a las situaciones de represalias o prácticas desleales/antisindicales sino también a casos en que el acto del empleador es ilegal (registrar, abrir o interceptar comunicaciones privadas ${ }^{92}$, emplear técnicas invasivas de interrogación ${ }^{93}$ ), arbitrario (desvincular conforme a la ley pero sin una explicación razonable $\left.{ }^{94}\right)$ o cuando la ley expresamente resuelve la controversia (v.gr., las exigencias del artículo 154 del Código). Si a estos se añaden aquellos que previsiblemente producirán efectos irreversibles en los derechos del trabajador, pueden generar lesiones de especial gravedad o está en juego un aspecto inviolable del derecho fundamental, la verdad es que el margen para la ponderación optimizadora ha quedado significativamente reducido.

\section{El ESPACiO QUE RESTA PARA EL TEST PRINCIPIALISTA, ES MARGINAL O NULO}

Si al amplio espacio en que cabe subsumir se añade que la subsunción es en algún grado inevitable tratándose de la adjudicación de derechos fundamentales, el resultado no solo es que se ha reducido el margen para la ponderación sino que poco o nada parece quedar para la versión optimizadora, pues en dicho espectro los aspectos tutelables de los derechos fundamentales del trabajador son discernibles con prescindencia de los del empleador, lo que altera uno de los ejes del principialismo.

Más allá de si la determinación de la frontera cuyo traspaso compromete un derecho o su contenido esencial supone llevar a cabo una tarea de delimitación, el carácter casuístico de la determinatio exige reconocer aspectos sensibles en el contenido de los derechos fundamentales que en algún grado deben ser representados apriorísticamente. La tutela del contenido inviolable de un derecho sería inoperante sin una idea anticipada acerca de aquello que no es sacrificable, bastando constatar que la injerencia actual o potencial en tal esfera generaría una lesión grave o produciría un efecto irreversible de no ordenarse una oportuna tutela preventiva o impeditiva de la reiteración, si ya ha acaecido.

Esto puede ser ilustrado con un caso clásico que ocurrió con el despido de una trabajadora invocándose el incumplimiento grave de las obligaciones contractuales. De la lectura de una conversación en Messenger, se habría descubierto que ella había entregado información confidencial del empleador a la empresa que esta fiscalizaba. El fallo acude a la optimización y concluye que la conducta era desproporcionada atendido el "contenido

91 Inspección PRovinCial del TRABAjo de SANTIAGo CON TP ChILE (2010), citado por Gamonal (2015) pp. 9798, donde refiere al caso de una trabajadora víctima de burlas por sus creencias religiosas "con expresiones como 'vieja loca, perra musulmana' ", entre otras medidas vulneradoras de su honra.

92 Ferrada (2008) pp. 261 y ss., y Silva (2011) p. 41, en un caso-Madrid CON SociedAd DE PROFESIONALES KRONOS LTDA (2008) citado enseguida- que suele ser visto como señero de la ponderación entre la medida de intercepción por el empleador de la comunicación privada de la trabajadora, muestran que era claro que "el empleador no tenía fundamento constitucional o legal alguno para interceptar, abrir o registrar la comunicación privada", por lo que nada había que ponderar.

93 Correa con Hipermercado San Pablo (2009).

94 Araos con Express de SANTIAGo UNo S.A. (2013). 
irrelevante" de la información ${ }^{95}$. Con independencia del resultado del fallo, dicho enfoque no solo hace trizas la inviolabilidad de este derecho sino que queda expuesto a ulteriores invasiones dependiendo de la "relevancia" de la información.

Tal perspectiva disuelve el contenido del derecho, pues condiciona la licitud o ilicitud de invadir las comunicaciones del trabajador al contenido de estas. Así, la relevancia del contenido habría de ponderarse con la relevancia del interés invocado al otro lado de la balanza. Esto, sin considerar que este derecho suele garantizar el continente de la comunicación privada antes que un contenido determinado ${ }^{96}$ frente a la amenaza de un tercero, que sin ser imparcial (empleador) se arroga el poder de traspasar dicha frontera ${ }^{97}$. Además el criterio optimizador estimula a que el derecho sea expuesto a ulteriores sacrificios, pues incentiva a que el empleador revise las comunicaciones privadas de sus trabajadores, que en el evento de encontrar algo interesante podría irle bien bajo la lógica principialista de la proporcionalidad en sentido estricto ${ }^{98}$.

Resultados como estos son lo que normas como los artículos 485 y 492 pretenden evitar: que las injerencias en aspectos sensibles de los derechos del trabajador puedan estimarse proporcionadas o justificadas no obstante no quedar nada in concreto del contenido del derecho del trabajador a la reserva de sus comunicaciones. Otros ejemplos también ilustran la inexorabilidad de la subsunción en esta materia. Así, la orden que autoriza a los trabajadores (de un call center) para ir al baño en contadas ocasiones o en un máximo de escasos minutos durante la jornada, difícilmente sería considerada una vulneración grave al derecho a la integridad síquica o una infracción a la prohibición de imponer apremios ilegítimos, si no se concibiera apriorísticamente que hay contenidos no negociables en los derechos fundamentales, sea que se refieran a un aspecto esencial del contenido de la integridad síquica, sea que se trate de prohibiciones amplias donde la esfera de la garantía está inmunizada erga omnes (tortura, esclavitud).

¿Sería pertinente acudir al TP frente a una cláusula contractual que prohíbe la manifestación de opiniones políticas en el lugar de trabajo? ¿No bastaría constatar que tal acto constituye un impedimento grave al ejercicio de la libertad de expresión más allá de la decisión prudencial de cada persona de emitir ciertas opiniones o dejar de hacerlas en ciertas circunstancias? En sentido análogo, ¿no sería un caso de trasgresión intolerable a la intimidad del trabajador la medida que autoriza colocar cámaras en la zona de higiene y aseo

\footnotetext{
95 MADRID CON SOCIEDAD DE PROFESIONALES KRONOS LTDA (2008) c. $7^{\circ}$.

96 FerRADA (2008) p. 260: "existe una prohibición de acceder, utilizar e invocar cualquier información contenida en estos canales privados, cuando ello pudiese significar el desconocimiento del derecho en su esencia. Luego si la transgresión es tan insoportable, por afectar el núcleo mismo del derecho protegido, será irrelevante el contenido de la comunicación, por lo que incluso, refiriendo temas que pudieran interesar a la empresa, no podrían ser utilizados ni invocados".

97 La doctrina y jurisprudencia han sido conteste en afirmar que el contenido de las comunicaciones privadas es inviolable para el empleador o para cualquier tercero distinto al destinatario de la información privada. Por ejemplo, es el criterio con el que el TC ha venido fallado el contenido de este derecho.

98 MARZi (2010) p. 135.
} 
de los trabajadores por mucho que dicha instalación esté incorporada en el reglamento, se aplique impersonalmente y sea conocida por los afectados?? .

Otros casos también configuran una vulneración irreversible a los derechos del trabajador sin necesidad de acudir a TP alguno. Las expresiones vejatorias del empleador a una trabajadora, por su ascendencia mapuche, son un claro ejemplo de lesión a su honra y de discriminación ${ }^{100}$, que hace inconducente posponer la conclusión de infracción a la espera de si la libertad de expresión del empleador podría contrapesar la lesión padecida. Más allá de si los ejemplos son una infracción a una garantía formulada en términos absolutos (prohibición de apremios ilegítimos) o entorpecen el derecho a la integridad psíquica al punto de comprometer su libre ejercicio (parte del contenido esencial del artículo 19 No 26), ellos muestran que admitido que el derecho está seriamente constreñido, la ponderación no solo es innecesaria sino que es contraproducente con los fines protectores de la tutela laboral. En otro orden de casos, la prohibición contractual de vincularse sentimentalmente con algunos de sus pares de la empresa mandante, o con cualquier persona relacionada directa o indirectamente con los servicios de que se desarrolla es una cláusula que compromete con tal intensidad el derecho a la vida privada, que su aplicación forzaría a los afectados a abandonar el trabajo para iniciar, mantener o consolidar una relación afectiva, con lo cual se infringiría además la libertad de trabajo.

No solo parece contraintuitivo someter a ponderación lo que se considera que no es ponderable sino que la proporcionalidad tampoco presta una guía en casos donde podrían estar en juego aspectos sensibles del derecho. ¿Tiene sentido afirmar que la inspección (idónea y aleatoria según el artículo 495) por el empleador de la bitácora personal del trabajador podría justificarse con miras a los derechos de este, una vez que se ha estimado anticipadamente que el diario de vida, cualquiera sea su contenido, es parte del derecho a la intimidad e inviolabilidad de los documentos privados del trabajador frente a quien no es un tercero imparcial? No parece consistente afirmar que la afectación, ya estimada vulneradora de un derecho, deje de serlo por la legitimidad que resultaría de brindar tutela al derecho contrapuesto ${ }^{101}$.

Lo expuesto muestra, primero, que la vulneración al derecho del trabajador es discernido con prescindencia del derecho fundamental del empleador ${ }^{102}$, más allá de la calificación jurídica de si la aplicación de la cláusula, del reglamento o de una medida del empleador supone contravenir una prohibición absoluta en materia de derechos o la garantía que protege el contenido esencial de aquellos, lo cual hace inevitable la subsunción. Segundo, que las hipótesis de subsunción, con o sin ponderación, pueden tener lugar incluso bajo el

\footnotetext{
99 Asumimos que estos ejemplos corresponden a esferas infranqueables del derecho para al empleador, pero no para el Ministerio Público (con las autorizaciones judiciales) ni para el juez (con las garantías a partir del artículo 9 del Código Procesal Penal que exige autorización judicial a toda actuación que pueda menoscabar derechos fundamentales del imputado o de un tercero).

100 DireCCIÓN REGIONAL dEL TRABAjO CON ENVASES EXPORTABLES (2010).

101 En un sentido análogo García Amado (2014) p. 57.

102 Ferrada (2010) p. 208, donde advierte que la protección que brinda la tutela a los trabajadores no se explica por la oposición de los derechos de ambas partes sino como un "análisis jurídico específico de las facultades del empleador y el contenido de ciertos derechos fundamentales de los trabajadores".
} 
ejercicio de un poder legalmente conferido pero arbitraria o abusivamente aplicado. Así, una medida adoptada en virtud de la potestad de control del empleador $-v$. gr., el uso indebido de cámaras de seguridad- puede vulnerar el derecho fundamental de un trabajador no obstante que la instalación de los aparatos se haya llevado a cabo de conformidad a las exigencias legales exigidas por artículo 154 del Código.

\section{CONCLUSIONES}

1. Las normas del Código del Trabajo que estructuran el procedimiento de tutela de los derechos fundamentales del trabajador no solo no consagran test de proporcionalidad alguno, sino que las disposiciones legales sobre la tutela laboral difícilmente se articulan con la noción que concibe a los derechos fundamentales como principios optimizables.

2. El artículo 485 exige que las limitaciones impuestas a los derechos fundamentales del trabajador respeten su contenido esencial, lo que obliga a subsumir, excluyendo o reduciendo la ponderación. Se adhiera a una idea absoluta o relativa del contenido esencial, suelen reconocerse aspectos no derrotables en los derechos, lo que dificulta la operatividad de la proporcionalidad optimizadora, que no reconoce puntos del todo inviolables en aquellos.

3. La subsunción es inexorable, en algún grado o fase, lo cual no solo contraviene los supuestos del test optimizador sino que hace innecesario acudir a él. Difícilmente puede discernirse si un acto del empleador afecta el contenido de un derecho del trabajador si no tenemos una representación previa acerca de lo que el derecho deja adentro y deja afuera de su resguardo. Sin tal operación apriorística no es posible determinar luego si, por ejemplo, la honra del trabajador ha sido menoscabada con ocasión de un despido acompañado de agresiones verbales.

4. Las normas generales del Código sobre la tutela laboral tampoco se condicen con la versión alexiana del test, pues acuden a expresiones perentorias que representan un lenguaje de esferas intocables que se aviene más bien con las reglas que con los principios, esto es, con la subsunción antes que con la ponderación.

5. Hay aspectos de los derechos fundamentales cuyos mandatos calzan más bien con las reglas, pues ordenan algo en términos específicos y categóricos $(v$. gr., no ser discriminado por color de piel) o contienen aspectos ( $v . g r$., intimidad fisiológica) que difícilmente son ponderables con los derechos de un tercero (empleador) que además no es imparcial (debido proceso).

6. La resistencia de los derechos fundamentales a ser encasillados como principios optimizables se explica también porque su resguardo efectivo no puede depender del "peso" o "valor" del derecho que aparece en contraposición. No hay violaciones proporcionadas a los derechos fundamentales. Una expresión vejatoria al trabajador despedido es siempre denigrante, con prescindencia del derecho invocado por el empleador.

7. El Código ordena subsumir no solo en casos calificados sino también en toda infracción al contenido esencial de los derechos fundamentales (artículo 485), y asimismo, en aquellas situaciones que produzcan efectos irreversibles en los derechos del trabajador (artículo 492), las que configuran supuestos legales que expanden el espectro para la sub- 
sunción (con la consecuencial declinación para la ponderación principialista) bastante más allá de las hipótesis admitidas por la generalidad de los autores.

8. Lo dicho exhibe que las premisas sobre las que se erige la versión optimizadora del test no solo encajan dificultosamente con los supuestos legales de la tutela laboral articulada por el Código, sino que riñen con la finalidad indiscutida de esta reforma legislativa, cual es la protección de los derechos fundamentales del trabajador.

\section{BIBLIOGRAFÍA CITADA}

Aldunate Lizana, Eduardo (2008): Derechos fundamentales (Santiago, LegalPublishing).

Alvarado Marambio, José Tomás (2016): "Inconmensurabilidad de los valores básicos y proporcionalismo. presupuestos filosóficos de la interpretación proporcionalista de los derechos fundamentales", Revista Chilena de Derecho, vol. 43 No 1: pp. 311-334.

Arnold, Rainer, Martínez Estay, José Ignacio y Zúniga Urbina, Francisco (2012): "El principio de proporcionalidad en la jurisprudencia del Tribunal Constitucional", Estudios Constitucionales, vol. 10, No 1: pp. 65-116.

AleXY, Robert (1989): Teoría de la argumentación juridica: La teoría del discurso racional como teoría de la fundamentación jurídica (trad. M. Atienza e I. Espejo, Madrid, Centro de Estudios Constitucionales).

AlEXY, Robert (1994): "Derechos individuales y bienes colectivos" en Garzón, Ernesto y Malem, Jorge, El concepto y la validez del Derecho (Barcelona, Gedisa) pp. 179-207.

AleXY, Robert (2002): A Theory of Constitutional Rights (New York, Oxford U. Press).

Alexy, Robert (2002b): "Epílogo a la Teoría de los Derechos Fundamentales" (trad. Carlos Bernal Pulido), Revista Española de Derecho Constitucional, vol. XX, N66: pp. 13-64.

AleXY, Robert (2003): Tres escritos sobre los derechos fundamentales y la teoría de los principios (trad. Carlos Bernal Pulido, Bogotá, Editorial Universidad Externado de Colombia).

Alexy, Robert (2003a): “On balancing and Subsumption. A Structural Comparison”, Ratio Juris, vol. 16, No 4: pp. 433-449.

BARAK, Aharon (2012): Proportionality: Constitutional Rights and their Limitations (Cambridge, Cambridge University Press).

BAŞAK, Çalı (2007): "Balancing Human Rights? Methodological Problems with Weights, Scales and Proportions", Human Rights Quarterly, vol. XXIX, No 1: pp. 258.

Borowsky, Martín (2000): "Las restricción de los derechos fundamentales", Revista Española de Derecho Constitucional, No 159: pp. 29-56.

CaAmaño, Eduardo (2006): "La eficacia de los derechos fundamentales en las relaciones laborales y su reconocimiento por la Dirección del Trabajo", Revista de Derecho de la Pontificia Universidad Católica de Valparaíso, vol. XXVII, No 1: pp. 19-44.

Carrizosa Prieto, Esther (2004): "El principio de proporcionalidad en el Derecho del Trabajo", Revista Española de Derecho del Trabajo, No 123: pp. 471-510.

Cassagne, Juan Carlos (2008): "Prohibición de la arbitrariedad y el control de la discrecionalidad administrativa por el poder judicial”, La Ley, Año LXXII, No 187: pp. 1-22.

Christoffersen, Jonas (2009): Fair balance: proportionality, subsidiarity and primarity in the European Convention on Human Rights (Leiden/Boston, Nijhoff Publishers). 
Clayton, Richard y Tomlinson, Hugh (2009): The Law of Human Rights (Oxford, Oxford University Press).

Contreras, Cristian y Aguilar, Gonzalo (2007): "El efecto horizontal de los derechos humanos y su reconocimiento expreso en las relaciones laborales en Chile", Ius et Praxis, vol. XIII, $\mathrm{N}^{\circ} 1$ : pp. 205-243.

Covarrubias Cuevas, Ignacio (2013): "La renuencia del Derecho Británico a la regla optimizadora en el test de proporcionalidad (y la constatación del mismo resultado en el TC chileno)", en Ortiz, David y Aquize, Katty (edit.), Constitucionalismo y Principio de Proporcionalidad, Tomo V (Ara Editores Perú-Colombia) pp. 470-501.

Covarrubias Cuevas, Ignacio (2014): “¿Emplea el Tribunal Constitucional el test de proporcionalidad?”, Estudios Constitucionales, vol. XII, No 1: pp. 163-237.

Covarrubias Cuevas, Ignacio (2015): "El test de proporcionalidad que se promueve en la tutela de derechos fundamentales con las premisas a las que se adhiere", Revista de Derecho de la Pontificia Universidad Católica de Valparaíso, vol. XLV: pp. 261-287.

Craig, Paul (2003): Administrative Law (London, Sweet \& Maxwell).

Fernández, Tomás Ramón (1991): Arbitrariedad y Discrecionalidad (Madrid, Editorial Civitas).

Ferrada Bórquez, Juan Carlos (2008): "Abriendo camino en la tutela de derechos fundamentales en materia laboral: buenas intenciones, malos instrumentos", Revista de Derecho (Valdivia), vol. XXI, No 2: pp. 251-271.

Ferrada Bórquez, Juan Carlos y Walter, Rodolfo (2011): "La protección de los derechos fundamentales de los trabajadores en el nuevo procedimiento de tutela laboral", Revista de Derecho (Valdivia), vol. XXIV, No 2: pp. 91-111.

Fuentes Olmos, Jessica (2012): "La defensa de las partes en el procedimiento de tutela laboral fundado en el derecho a la honra del trabajador", Revista de Derecho de la Pontificia Universidad Católica de Valparaíso, vol. 39, No2: pp. 141-160.

Gamonal Contreras, Sergio (2008): El procedimiento de tutela de derechos fundamentales (Santiago, LegalPublishing, segunda edición).

Gamonal Contreras, Sergio (2015): La eficacia diagonal u oblicua y los estándares de conducta en el Derecho del trabajo (Santiago, Thomson Reuters).

García Amado, Juan Antonio (2014): “Ponderación y subsunción: métodos intercambiables. La esencial intercambiabilidad del método ponderativo subsuntivo y el interpretativo-subsuntivo y las ventajas e inconvenientes de cada uno", en GARCía, Mayolo y Moreno, Rodolfo (coord.), Argumentación Jurídica. Fisonomía desde una óptica forense (México, Instituto de Investigaciones Jurídicas UNAM): Disponible en: http://www. garciamado.es/category/publicaciones-academicas/

Gewirth, Alan (1984): “Are There Any Absolute Rights?” en Waldron, Jeremy (edit.) Theory of Rights (Oxford, Oxford Readings in Philosophy).

Grimm, Dieter (2007): "Proportionality in Canadian and German constitutional jurisprudence", University of Toronto Law Journal, vol. LVII, N 2: pp. 383-397.

Guastini, Riccardo (1999): "Los principios en el derecho positivo" (trad. de Jordi Ferrer Beltrán), en Distinguiendo. Estudios de Teoría y Metateoría del Derecho (Barcelona, Gedisa). 
Guibourg, Ricardo (2013): "Sobre los derechos", Análisis Filosófico, XXXIII, No 1: pp. 6780.

Habermas, Jürgen (2001): Facticidad y validez (Madrid, Trotta).

HaRT, Herbert Lionel Adolphus (1994): The Concept of Law (Oxford: Clarendon Press, segunda edición).

LARIgUet, Guillermo (2005): "Conflictos trágicos y ponderación constitucional. En torno a algunas ideas de Gustavo Zagrebelsky y Riccardo Guastini”, Diritto \& Questioni Pubblice, Universitá degli Studi di Palermo No 5: pp. 67-85.

Lester, Anthony y Pannick, David (2004): Human Rights: Law and Practice (Londres, LexisNexis - Butterworths Law).

López Escarcena, Sebastian (2014): Indirect Expropriations in International Law (Massachusetts, Levuen Global Governance).

Marzi, Daniela (2010): “¿Quién le teme a los derechos fundamentales? Sobre el procedimiento de tutela de la Reforma Laboral", Anuario de Derechos Humanos 2010, Facultad de Derecho de la Universidad de Chile: pp. 131-139.

Marshall Barberán, Pablo (2007): "Los derechos fundamentales como valores", Revista Telemática de Filosofía del Derecho, No 10: pp. 207-228.

Melis, Christian (2011): Los derechos fundamentales de los trabajadores como límites a los poderes empresariales (Santiago, LegalPublishing).

Mella Cabrera, Patricio Eleodoro y Domínguez Montoya, Álvaro Eduardo (2012): "Conflicto de derechos constitucionales y juicio de tutela laboral en Chile: Estado doctrinal, legal y jurisprudencial”, Revista de Derecho de la Pontificia Universidad Católica de Valparaiso, No 39: pp. 177-219.

Nogueira Alcalá, Humberto (2010): "El principio de proporcionalidad y su aplicación en Sudamérica por la jurisdicción constitucional, con especial mención al Tribunal Constitucional chileno", en Carbonell, Miguel (coord.), El principio de proporcionalidad en la interpretación jurídica (Santiago, Librotecnia) pp. 353-403.

ÖRÜCÜ, Esin (1986): “The Core of Rights and Freedoms: The Limit of Limits”, en CAMPBeLl, Tom et al. (eds.), Human Rights: From Rethoric to Reality (Oxford, Basil Blackwell): pp. 37-59.

Palomo Vélez, Rodrigo (2007): "El rol de los principios en la aplicación del Derecho del Trabajo. Antecedentes conceptuales sobre el estado del arte en Chile", Revista Laboral Chilena, No 161: pp. 59-69.

Paredes, Felipe (2012): La garantía jurisdiccional de los derechos fundamentales en el ordenamiento jurídico, Tesis para optar al grado de Doctor de la Universitat Pompeu Fabra. Director: Alejando Saiz (Barcelona, Universitat Pompeu Fabra). Disponible en: http:// www.tdx.cat/bitstream/handle/10803/85415/tfipp.pdf;jsessionid=1F4DB1020029FBF D411909B5CEA0B4F5? sequence $=1$.

Paredes, Felipe (2015): "La tutela jurisdiccional de los derechos fundamentales: una propuesta en clave democrática”, Revista Chilena de Derecho, vol. 42, No 1: pp. 245-265.

Petersen, Niels (2013): "Proportionality and the Incommensurability Challenge -Some Lessons from the South African Constitutional Court", Public Law \& Legal Theory Re- 
search Paper, Series Working Paper No 13-07: pp. 1-23. Disponible en http://sr.nellco. org/cgi/viewcontent.cgi?article=1385\&context=nyu_plltwp

Petersen, Niels (2017): Proportionality and Judicial Activism. Fundamental Rights Adjudication in Canada, Germany and South Africa (Cambridge, Cambridge University Press).

Prieto Sanchís, Luis (1990): Estudios sobre derechos fundamentales (Madrid, Debate).

Raz, Joseph (1975): Practical Reason and Norms (Oxford, Oxford University. Press).

Rivers, Julian (2006): "Proportionality and variable intensity of review", Cambridge Law Journal, vol. 65, $\mathrm{N}^{\circ}$ 1: pp. 174-207.

Silva IrrarázAVAL, Luis Alejandro (2011): "Supremacía constitucional y tutela laboral”, Revista de Derecho (Valdivia), vol. XXIV N 1: pp. 31-48.

Sото Kloss, Eduardo (2010): Derecho Administrativo. Temas Fundamentales (Santiago, LegalPublishing, segunda edición).

STEIN, Thorsten (2005): "Proportionality Revisited - Überlegungen zum Grundsatz der Verhältnismässigkeit im internationalen Recht”, en Dicke, Klaus et al (edit.) Weltinnenrecht: liber amicorum Jost Delbrück (Berlin, Duncker \& Humblot) pp. 729-731.

Susnjar, Davor (2010): Propotionality, Fundamental Rights and Balance of Powers (Leiden, M. Nijhooff).

Ugarte Cataldo, José Luis (2007): "La tutela de derechos fundamentales y el Derecho del Trabajo: de erizo a zorro", Revista de Derecho, vol. XX, N²: pp. 49-67.

Ugarte Cataldo, José Luis (2009): Tutela de derechos fundamentales del trabajador (Santiago, Editorial Jurídica ConoSur).

Ugarte Cataldo, José Luis (2011): "Privacidad, trabajo y derechos fundamentales", Estudios Constitucionales, vol. IX, $\mathrm{N}^{\circ} 1$ : pp. 13-36.

Ugarte Cataldo, José Luis (2011a): "Los derechos en su nueva hora: la teoría externa de los derechos fundamentales", Revista de Derecho Universidad Católica del Norte, vol. 18, No 2: pp. 361-373.

Ugarte Cataldo, José Luis (2011b): La colisión de derechos fundamentales en el contrato de trabajo y el principio de proporcionalidad, Tesis para optar al grado de Doctor de la Universidad de Salamanca. Director: Manuel Palomenque (Salamanca, Universidad de Salamanca). Disponible en: http://dialnet.unirioja.es/servlet/tesis?codigo=26589.

Urbina, Francisco J. (2014): "Is it really that easy? A critique of proportionality and "balancing as reasoning”, Canadian Journal of Law \& Jurisprudence, vol. 27, $\mathrm{N}^{\circ} 1$ : pp. 167192.

Urbina, Francisco J. (2012): "A critique of proportionality", American Journal of Jurisprudence, vol. 57: pp. 49-80.

Urbina, Francisco J. (2017): A critique of proportionality and balancing (Cambridge, Cambridge University Press).

Van Der Walt, André J. (1999): Constitutional Property Clauses: comparative analysis (Clermont, JUTA).

Wade, William y Forsyth, Christopher (2004): Administrative Law (Oxford, Oxford University Press).

Waldrom, Jeremy (1993): "A Right-Based Critique of Constitutional Rights", Oxford J. Legal Studies, vol. XIII: pp 18-51. 
Webber, Grégoire (2009): The Negotiable Constitution: On the Limitation of Rights (Cambridge, Cambridge University Press).

Zagrebelsky, Gustavo (1995): El derecho dúctil. Ley, derechos, justicia (trad. Marina Gascón, Madrid, Trotta).

\section{NORMAS CITADAS}

Decreta con fuerza de ley $\mathrm{N}^{\circ} 1(16 / 01 / 2003)$, Código del Trabajo.

Convención Europea de Derechos Humanos (4/10/1950)

\section{JURISPRUDENCIA CITADA}

ARAos con Express de SANTIAGo UNo S.A. (2013): Segundo Juzgado de Letras del Trabajo de Santiago, RIT T-66 (acción de tutela de derechos fundamentales en materia laboral).

Inspección Provincial del TRABAjo con Asociación Indígena NeWENTULEAIN (2014): Juzgado de Letras del Trabajo de Nueva Imperial, RIT T-2 (acción de tutela de derechos fundamentales en materia laboral).

Macaya con Clínica Dental Cumbre Sur s.a. (2014): Juzgado de Letras del Trabajo de Concepción, 29 octubre de 2014 (acción de tutela de Derechos Fundamentales en materia laboral). Disponible en: http://laboral.poderjudicial.cl/SITLAPORWEB/InicioAplicacionPortal.do

Dirección REgional del TRABajo con ENVASES EXPORTables (2010) Segundo Juzgado de Letras del Trabajo de Santiago, 19 de marzo de 2010 (acción de tutela de derechos fundamentales en materia laboral). Disponible en: http://laboral.poderjudicial.cl/SITLAPORWEB/InicioAplicacionPortal.do

GarRido con Fotografica Full Color Limitada (2010): Juzgado de Letras del Trabajo de Chillán, 29 de diciembre de 2010 (acción de tutela de derechos fundamentales en materia laboral). Disponible en: http://jurisprudencia.vlex.cl/vid/574819242.

Inspección Provincial del TRabajo de SANTiago con TP Chile ltda (2010): Primer Juzgado de Letras del Trabajo de Santiago, 31 de agosto de 2010 (acción de tutela de derechos fundamentales en materia laboral). Disponible en: http://laboral.poderjudicial.cl/SITLAPORWEB/InicioAplicacionPortal.do

Correa con Hipermercado San Pablo (2009): Segundo Juzgado de Letras del Trabajo de Santiago, RIT T-33 (acción de tutela de derechos fundamentales en materia laboral).

MAdRID CON SOCIEDAD DE PROFESIONALES KRONOS LTDA (2008): Juzgado de Letras del Trabajo de Copiapó, 15 de Septiembre de 2008 (acción de tutela de derechos fundamentales en materia laboral). Disponible en: http://laboral.poderjudicial.cl/SITLAPORWEB/InicioAplicacionPortal.do 
